\title{
Migration of PFO closure device and entrapment within tricuspid valve leading to tricuspid regurgitation: Surgical correction of an extremely rare complication after transcutaneous PFO closure
}

\author{
Myat Thet ${ }^{1}$, Amir Sepehripour ${ }^{1}$, Abed Atieh ${ }^{1}$, and Carmelo DiSalvo ${ }^{1}$ \\ ${ }^{1}$ St Bartholomew's Hospital
}

August 23, 2020

\begin{abstract}
A 41-year-old lady was referred to tertiary cardiothoracic surgery centre following embolisation of patent foramen ovale (PFO) closure device to septal leaflet of tricuspid valve with reopening of PFO. Two years earlier, she presented with thalamic stroke, and she was found to have a PFO following investigations. The following year she underwent transcatheter closure. Six months after the percutaneous closure, she presented again with significant periods of shortness of breath. Imaging studies revealed the migration and embolisation of PFO closure device to the septal leaflet of tricuspid valve with reopening of the foramen and significant tricuspid valve regurgitation. She underwent open heart surgery using cardiopulmonary bypass for retrieval of the device, closure of the foramen and repair of the tricuspid valve. The patient recovered well without any significant issues following surgery.

\section{Hosted file}

Manuscript - Migration of PFO closure device onto tricuspid valve with tricuspid regurgitation and reop available at https://authorea.com/users/352850/articles/477155-migration-of-pfo-closuredevice-and-entrapment-within-tricuspid-valve-leading-to-tricuspid-regurgitationsurgical-correction-of-an-extremely-rare-complication-after-transcutaneous-pfo-closure
\end{abstract}



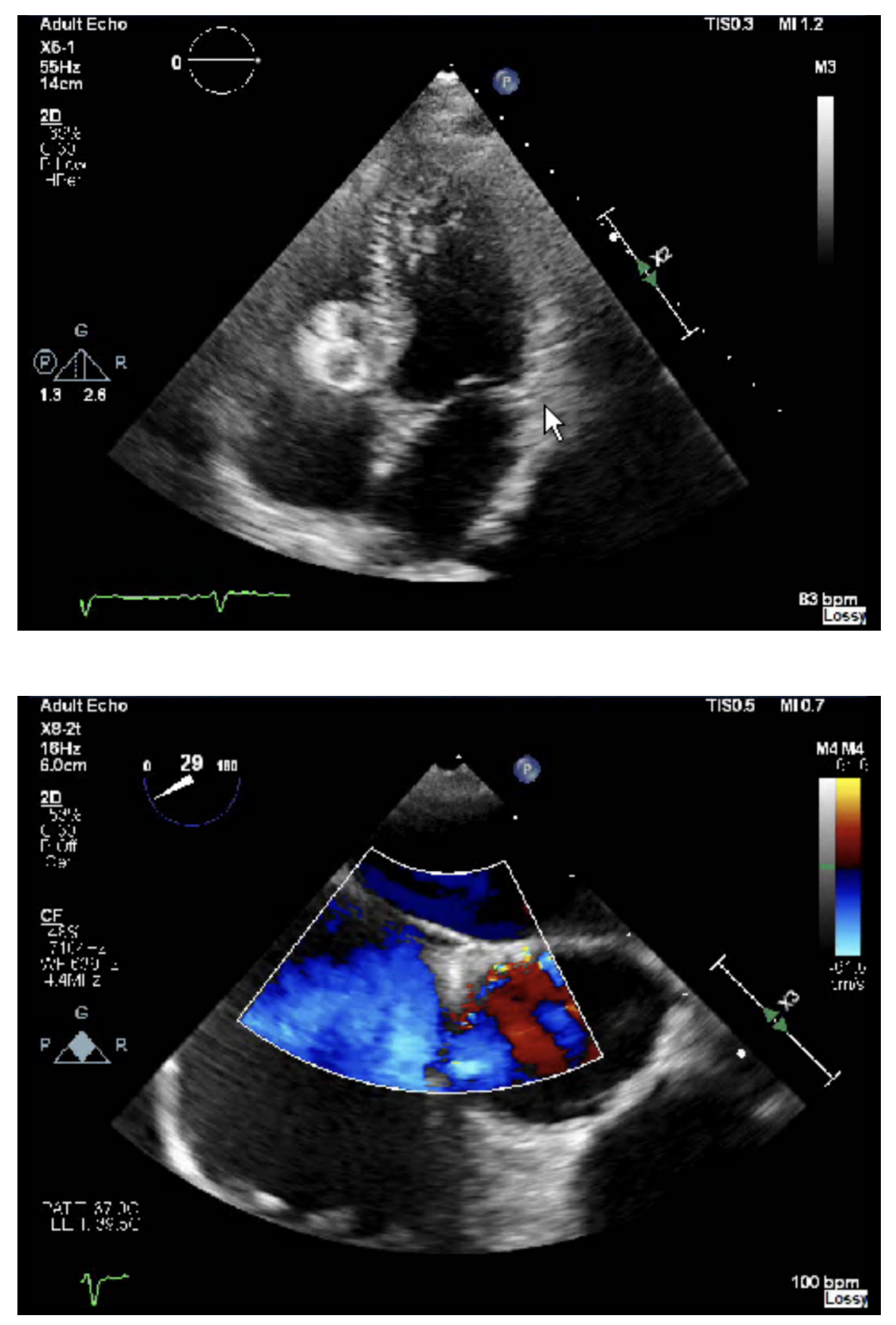


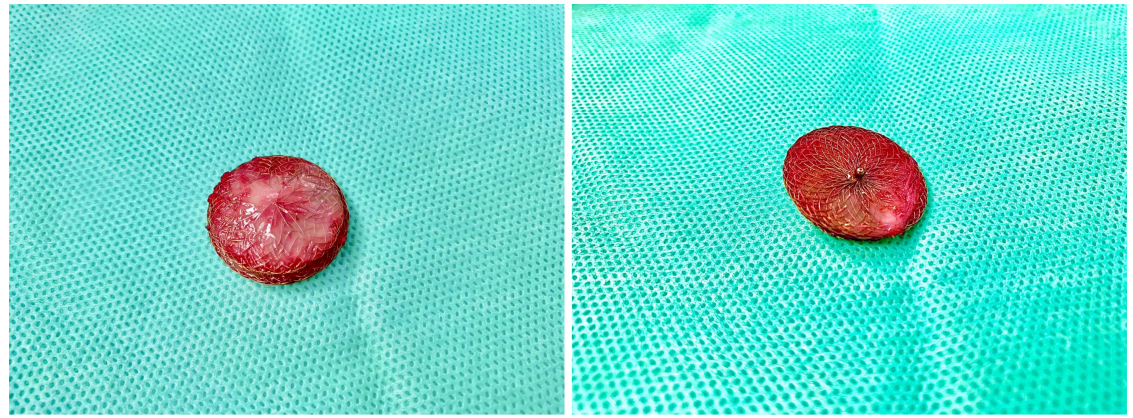

